\title{
Anti-Corrosion Silica-Based Hybrid Coatings for the Protection of AA2024 Alloy
}

\author{
$\left\{\text { M. Zoriany }{ }^{*}, \text { A. Nashaat, Y. El-Shaer, M. Gobara }\right\}^{\dagger}$
}

\begin{abstract}
In this work, design and preparation of different hybrid ceramic coatings based on Diglycidyl ether of Bisphenol A (Epoxy) and 3-Glycidyloxypropyl trimethyloxysilane (GLYMO) by sol-gel technique was studied. The obtained hybrids coatings were cured by using different hardners. Microstructure assessment of the prepared hybrids was investigated using FTIR. The morphology of the hybrid (silica/epoxy) coatings has also been studied by scanning electron microscopy (SEM). Evaluation of selected mechanical properties (adhesion, and hardness) were performed. In addition, the thermal properties were investigated using thermogravimetric analysis (TGA). The investigation of the different prepared coatings for protection against corrosion were studied based on EIS measurements. The results showed that the silica content plays an important role in determining the morphology as well as the mechanical and thermal properties of the coatings. The EIS results showed an improvement in the corrosion resistance of the hybrid coatings with increasing the silica content up to a certain extent. However, further increase in the silica content, leads to a descent in the corrosion resistance.
\end{abstract}

Keywords: sol-gel, silica, GLYMO, APTES, anti-corrosion, epoxy, hybrid, aluminium, AA2024.

\section{Introduction}

Aluminium alloy 2024 has been widely used in aircraft industry considering its strength to weight ratio and good mechanical properties. However, it is susceptible to pitting corrosion where it comprises cathodic intermetallic particles with respect to the aluminium matrix. Chromate coatings have previously been used on this alloy for protection against corrosion. However, different coatings have been proposed lately to replace these coatings due to their toxicity and carcinogenic effects. Hybrid silica sol-gel coatings are some of these alternatives. In fact, silica sol-gel coating forms an inactive barrier between the metal substrate and the corrosive environment. Nevertheless, prolonged exposure to corrosive environment enforces the penetration of oxygen and water through these coatings to some extent.

Hybrid coatings compromise two components; an organic one that is responsible for toughness, adhesion and elasticity. While the other is inorganic that characterizes some other properties like hardness and wear resistance. Silica sol-gel coatings form van der Waals bonds with the metallic substrate. These bonds transform to a stable covalent bond during the curing process. In addition, these coating can form a silica rich Al-oxide layer, which blocks the pores of $\mathrm{Al}$ oxide, consequently, it can protect aluminium from corrosion.

m.yossry@mtc.edu.eg

Egyptian Armed Forces, Egypt. 
Epoxy-silica coatings were studied by a number of researchers. Generally, epoxy resins have superior chemical and corrosion resistance, high adhesion, and curability at ambient temperature. However, they suffer from poor thermal and weathering stabilities, reduced mechanical properties and unsuitable cutting properties. This limits the epoxy resins in highperformance applications [1]. Using silica inorganic precursor within the epoxy resins to form epoxy-silica hybrid materials may improve these limits [2]. Nevertheless, sufficient evidences of phase-separation within silica-rich network were obtained. This reveals the incompatibility of epoxy resin with tetraethyloxysilane (TEOS). The compatibility between the organic and inorganic parts can be improved by using inorganic precursor that contains epoxy branch i.e. coupling agent such as 3-Glycidyloxypropyl trimethoxysilane (GLYMO).

The main corrosion process of AA2024 in chloride-containing electrolyte is pitting [3]. In such electrolyte, aluminum oxide layer cannot protect the alloy from corrosion. Hence, after suitable time of immersion, the chloride electrolyte diffuses into the coating/metal interface where the intermetallic particles, mainly $\mathrm{Al}_{2} \mathrm{MgCu}$, cover $3 \%$ of the aluminum alloy surface. Pitting usually appears around these particles. These particles have a nobler potential than that of the alloy matrix and consequently acting as a cathode with respect to the aluminum matrix, i.e. galvanic cell, and promoting the anodic dissolution of alloy matrix leading to autocatalytic pitting $[4,5]$. Accordingly, it can be concluded that barrier coatings forming an inactive barrier only can delay the corrosion process. However, these coatings cannot inhibit corrosion for prolong time of immersion.

In this study, silane-modified epoxy resins from pre-hydrolyzed GLYMO was consequently developed in the presence of a relative concentration of 3-aminopropyl triethoxysilane (APTES) and diethylene triamine (DETA) as curing agents. APTES was not only used as a curing agent but also to improve the solubility of the pre-hydrolyzed form of silica (from GLYMO) within the epoxy matrix and to increase the inorganic content. Therefore, hybrid silica sol gel coatings were prepared with different silica content. The coatings were applied on AA2024 then the corrosion behavior of them was examined in artificial sea water. The effect of silica content in the mechanical properties (hardness and adhesion) of these coatings was also investigated.

\section{Material and Methods}

\subsection{Materials}

As the organic phase precursor, DEGBA epoxy resin of EEW=450-500 g/equiv. was obtained from HUNTSMAN (China). The inorganic precursors, GLYMO and APTES (coupling agents) were obtained from Sigma-Aldrich, USA. The DETA curing agent (hardner) was obtained from $\mathrm{CDH}$, India. Acetone (solvent) as well as $\mathrm{HCl}$ (37 wt\% in water) was purchased from BDH, England. All reagents were used as received without any further modification or processing. Fig. 1 shows the chemical structures of the used precursors.
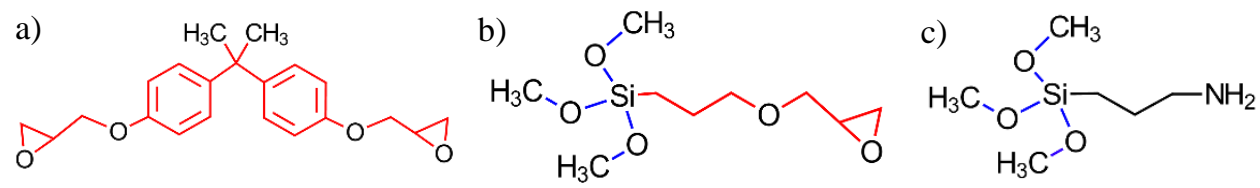

d)

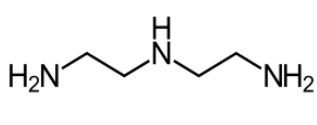

Fig. 1 The chemical structure of the used precursors.

a) DGEBA, b) GLYMO, c) APTES, d) DETA. 


\subsection{Coupons of AA2024 and Corrosive Media}

All electrochemical experiments were performed at ambient temperature using freshly prepared coupons of AA2024. Aluminium alloy 2024-T3 samples of dimensions $(2.54 \times 10.16 \times 0.156) \mathrm{cm}^{3}$ were obtained from Q-panel, USA. AA2024 Coupons of composition ((wt.\%) $\mathrm{Cu}(3.8-4.9), \quad \mathrm{Mg}(1.28), \quad \mathrm{Mn}(0.3-0.9), \quad \mathrm{Cr}(0.1), \quad \mathrm{Zn}(0.25), \mathrm{Ti}(0.15)$, $\mathrm{Si}(0.381), \mathrm{Fe}(0.5)$ and the remainder $\mathrm{Al})$ were cleaned with deionized water followed by ultrasonic cleaning in acetone and then dried for $30 \mathrm{~min}$ at $70{ }^{\circ} \mathrm{C}$ then stored in desiccator till their use in corrosion experiments.

\subsection{Preparation of Silica/Epoxy Sol-Gel Coating}

The sol-gel technique depends on a series of hydrolysis and condensation reactions as shown in equations (1-3), as follows:

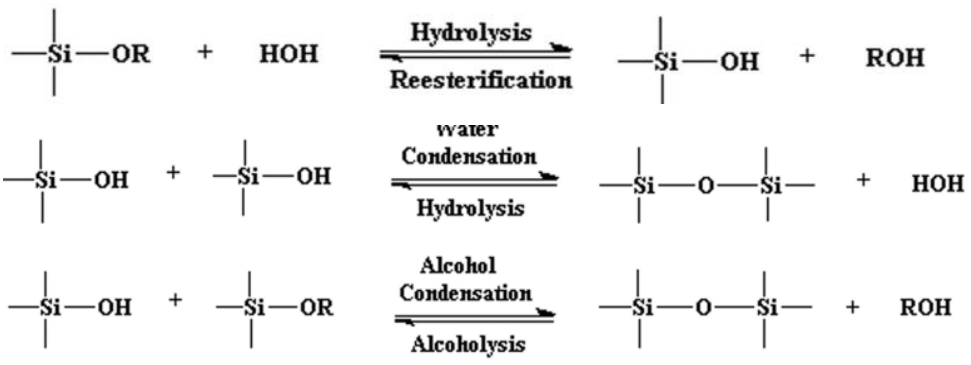

A mixture consisting of epoxy resin and GLYMO in the presence of acetone was prepared according to the wt. ratio of 1:1:6 respectively. The mixture was stirred for $15 \mathrm{~min}$. till the complete dissolution of the epoxy resin. Conc. $\mathrm{HCl}$ was added to the solution preserving a water ratio of 3 with respect to the amount of GLYMO, keeping the $\mathrm{pH}$ within the range of $4.5 \pm 0.3$. The solution was stirred for $1 \mathrm{hr}$. followed by heating to $100^{\circ} \mathrm{C}$ while stirring for another $1 \mathrm{hr}$. then the solution was left overnight. After $24 \mathrm{hr}$, the amount of the hardener to be added to each portion varied between two hardeners, DETA and APTES, according to Table 1. All samples were to be spray coated to a thickness of $50 \pm 5 \mu \mathrm{m}$.

Table 1. Different compositions used in the hybrid coat preparation

\begin{tabular}{c|c|c|c}
\hline \hline No. & $\begin{array}{c}\text { GLYMO: } \\
\text { Epoxy } \\
\text { ratio* }\end{array}$ & $\begin{array}{c}\text { Hardners } \\
\text { (APTES:DETA) } \\
\text { ratio* }\end{array}$ & $\begin{array}{c}\text { Prepared } \\
\text { sample } \\
\text { name }\end{array}$ \\
\hline 1 & $1: 1$ & $0: 1$ & A0 \\
2 & $1: 1$ & $1: 4$ & A1 \\
3 & $1: 1$ & $1: 1.5$ & A2 \\
4 & $1: 1$ & $1: 0.67$ & A3 \\
5 & $1: 1$ & $1: 0.25$ & A4 \\
6 & $1: 1$ & $1: 0$ & A5 \\
\hline \hline
\end{tabular}

*wt. ratio

\subsection{Characterization and Measurements}

FTIR analysis was performed using a JASCO 4100 FTIR spectrometer over the range of 400$4000 \mathrm{~cm}^{-1}$ at a resolution of $4 \mathrm{~cm}^{-1}$. Spectra with a high signal-to-noise ratio were obtained through the collection of 500 scans for each sample.

The surface morphologies of the used coupons were investigated using scanning electron microscopy (SEM, Zeiss EVO-10 microscopy). 
Thermogravimetric analysis (TGA) studies on the samples were executed on SHIMADZU TGA-50H Analyzer. The weight of each sample was (1-2) $\mathrm{mg}$ and the temperature increased from $35^{\circ} \mathrm{C}$ to $800^{\circ} \mathrm{C}$ with a heating rate of $10{ }^{\circ} \mathrm{C} / \mathrm{min}$. A normal oxidative atmosphere was maintained by the continuous flow of air at $10 \mathrm{ml} / \mathrm{min}$.

For comparing the corrosion behavior of different coating combinations applied to AA2024, electrochemical impedance spectroscopy (EIS) was used for evaluation in $3.5 \% \mathrm{NaCl}$ solution. EIS measurement gives a semi-quantitative data about the coating degradation process that occurs during the testing course. Using EIS results, it is possible to delve the corrosive behavior of prepared coatings deeply. In this study, Bode plots are used for identification of coating performance and description of the coating impedance. The impedance plots were investigated at low frequency range $(10 \mathrm{mHz})$ which represent the total resistance of the coating under continuous immersion.

Electrochemical corrosion experiments were carried out in a three-electrode type cell. For each experiment, a fresh coupon was used as working electrode with a saturated calomel electrode as reference electrode and platinum as auxiliary electrode.

Electrochemical Impedance Spectroscope (EIS) measurements using Gamry ${ }^{\mathrm{TM}}$ instrument model reference 600 . The AC signal with $\pm 10 \mathrm{mV}$ peak to peak perturbation in the frequency range from $3 \times 10^{4}$ to $10^{-2} \mathrm{~Hz}$ was applied in these measurements.

\subsection{Mechanical Testing}

The thickness of the prepared hybrid coat sprayed over the aluminium substrate was to be measured by the coat thickness gauge Kett LZ-330C.

The adhesion measurements were performed on double-lap joints with the coat prepared to be used as the adhesive material. The test was performed according to ASTM 5656 at room temperature on a GALDABINI QUASAR 100, which is a dual column benchtop testing machine detecting the end point of the test through the parallel length and not through extensometer. The initial applied load was set to be $10 \mathrm{~N}$ and the load was to be increased at a rate of $15 \mathrm{~N} / \mathrm{s}$.

The hardness measurements were performed on INSTRON TUKON 2100B from Winston instruments. Hardness measurements were specified for Vickers type indenter, in which a square impression indented within the coat's surface and the two diagonals are two be specified and measured through a microscope and software embedded with the instrument. The software found is responsible for calculating the hardness of the coat through the determination of the average of the diagonals' lengths, and substituting in equation (4) as follows:

$H_{v}=1.854 \frac{F}{d^{2}}$

where, $\mathrm{H}_{\mathrm{v}}$ represents the Vickers Hardness, $\mathrm{F}$ is the test load (in kgf) and $\mathrm{d}$ is the average distance of the concave part (in $\mathrm{mm}$ ). 


\section{Results and Discussion}

\subsection{FT-IR Analysis}

Using the Fourier Transform Infrared technique to investigate whether or not does the expected preparation scheme is followed, the spectra of the main precursors of the hybrid coat were studied individually and primarily as shown in Fig.2.

Separately, the spectrum of each precursor was investigated and the main structural bands were focused upon as shown in Fig. (2.a) and (2.b). Starting with DGEBA (Epoxy), the peaks aiming at both the benzene and the oxirane rings (found around 3045 and $915 \mathrm{~cm}^{-1}$ ) were specified. For the main ceramic-constituent precursor, GLYMO spectrum was clarified for the Si-O-C bands (at 1200-1000 $\mathrm{cm}^{-1}$ ) and the oxirane ring peaks [6-8].

The spectra of the prepared hybrid coats were compared to each other and it was found to be approximately identical. Therefore, a selected spectrum of sample A2 was shown in Fig. (2.c) as a representative for all hybrid coats. The spectrum was revised for the oxirane ring peaks at (3047 and $916 \mathrm{~cm}^{-1}$ ) that have almost diminished. Also, the bands related to the amino groups along with the hydroxyl groups at the ranges of $\left(3570-3200 \mathrm{~cm}^{-1}\right)$ and $\left(1620-1550 \mathrm{~cm}^{-1}\right)$ were highly recorded, indicating the breakage of the oxirane ring and the existence of uncondensed hydroxyl groups with a residual amount of the curing agent.

Aside from the oxirane ring, the $\mathrm{Si}-\mathrm{O}-\mathrm{C}$ bands were to be thoroughly studied. It is mentioned that the broad band of (1200-1000 $\left.\mathrm{cm}^{-1}\right)$ are assigned to all silica related compounds and it was hard to assign a specific band for such group[9]. Sometimes peaks within this range was assigned to Si-C bond while other was assigned to Si-O-Al [10], but the most has assigned the sharp peaks of the pure precursor to the symmetric and asymmetric stretching of the Si-O-C.

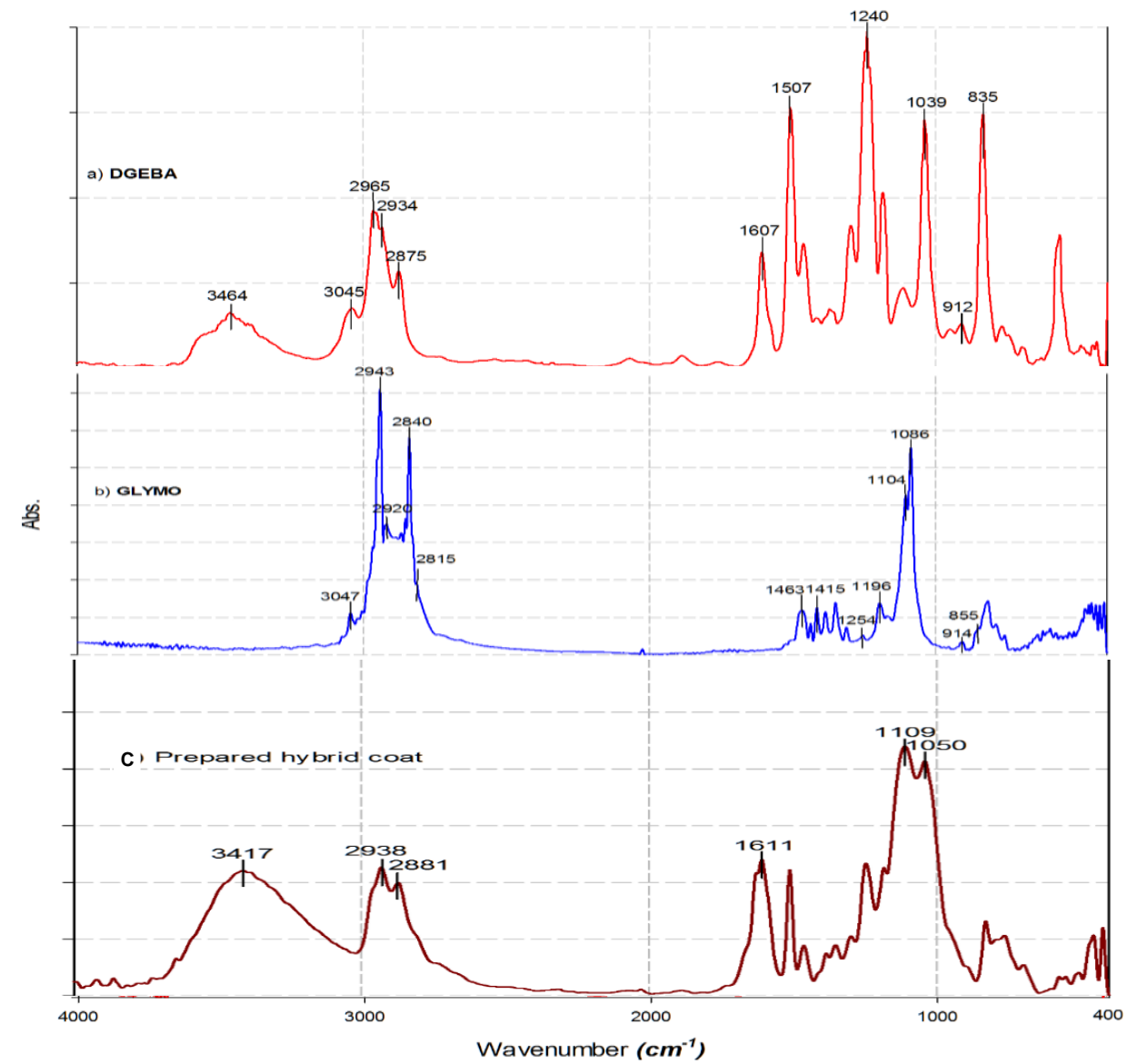

Fig. 2. FTIR spectra of a) DGEBA, b) GLYMO, c) The prepared hybrid coat 
Once the silica network are created, the sharp peaks are replaced with those broad peaks as exactly found here within our case in Fig. (2.c) at $\left(1050\right.$ and $\left.1109 \mathrm{~cm}^{-1}\right)$. Conservatively, a peak at the range of $3420 \mathrm{~cm}^{-1}$ is taking place form the hydrolyzed but uncondensed $\mathrm{Si}-\mathrm{OH}$ species. Also, the peak at $3420 \mathrm{~cm}^{-1}$ may indicates an adsorbed amount of water vapor or a contained residuals of the corresponding released alcohol $[11,12]$.

Therefore, it can be concluded that the prepared coat is totally cured with the curing agents to be slightly in excess. In addition, the silica network formation through the sol-gel technique is reported to be successful. Nevertheless, the contribution of the bonding between the silanol groups found as a result of hydrolysis and the hydroxyl groups resulted from the oxirane ring breakage may took place through a condensation reaction.

\subsection{Mechanical Characterization}

\subsubsection{Adhesion test}

In order to evaluate the adhesion strength of hybrid coatings, a double- lap joints were prepared and a pull-off adhesion test was applied according to ASTM 5656. Epoxy with GLYMO of ratio (1:1) by mass would be considered as the base coat and different ratios of APTES to DETA were to be applied as explained before. Using APTES as an another source of silica, has made the synthesis of a silica based hybrid coat more integrated. Appling the adhesion test for the prepared combinations had came up with the trend shown in Fig. 3.

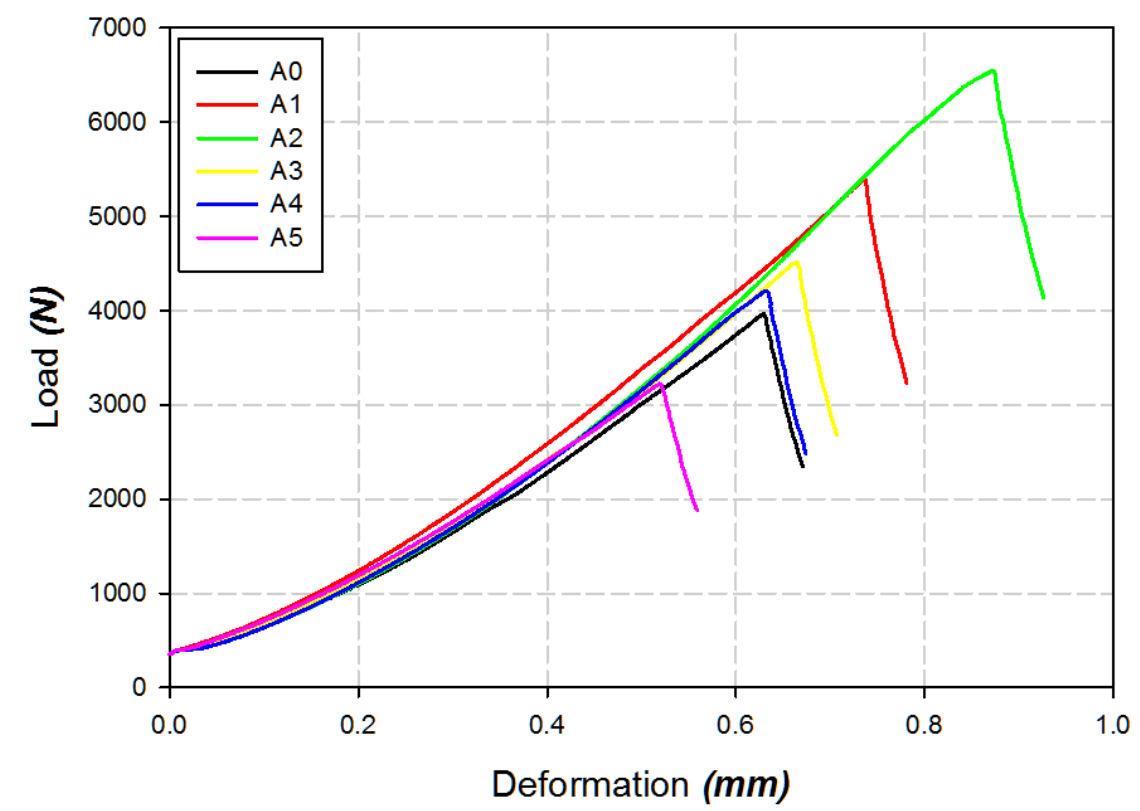

Fig. 3. Load-Deformation curves for the prepared hybrids

The load-deformation curves for different combination hybrid coatings were analyzed and the max. force applied as an indication for adhesion strength were assigned. As a result, the shear stress for a double area of $\left(2.5 \times 7 \mathrm{~cm}^{2}\right)$ Fig. 4 was concluded.

As shown in Fig. 4 that the introduction of APTES with a small ratio of A1 would offer a higher adhesion than that of the DETA only (A0), followed by a more adherent combination of A2. Then, the following combination of higher contribution of APTES to DETA (A3 and A4) have shown a gradual decrease reaching the minimum at APTES only (A5). The reason for the gradual increase in the adhesion strength at first is that with the introduction of APTES in small amounts a more homogeneous, compatible hybrid coat is formed. 


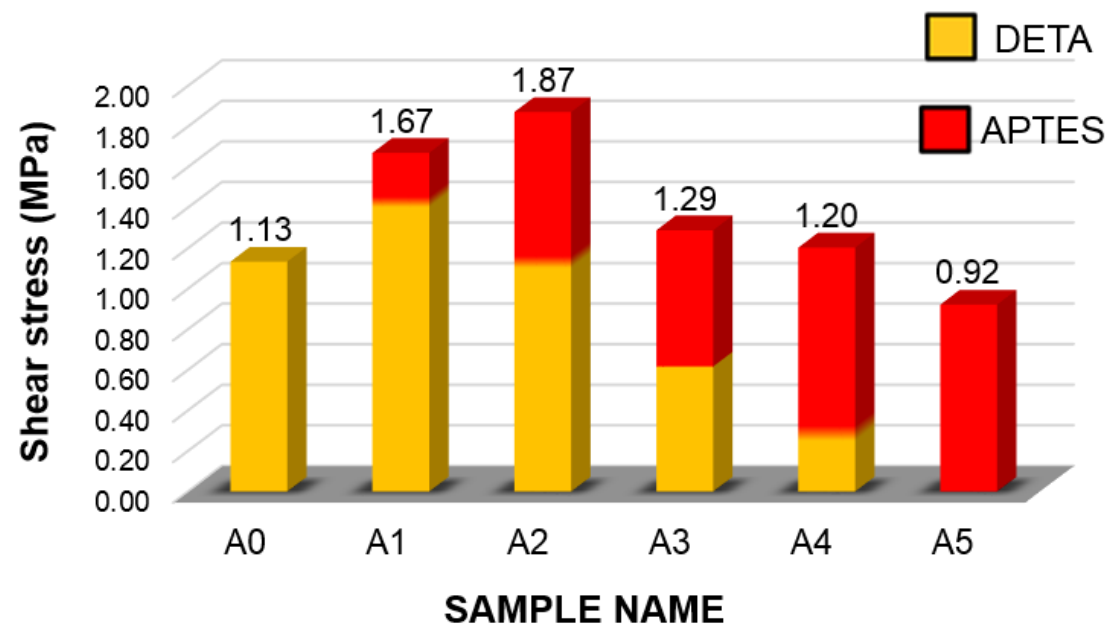

Fig. 4. Shear stress assigned for each hybrid combination

A more compatible coat would offer a contribution of the hydrolyzed silanol groups to the bonding with the substrate forming a Si-O-Al bond increasing adhesion. Further increase in the APTES ratio, would increase the formed $\mathrm{Si}-\mathrm{O}-\mathrm{Al}$ bonds on the expense of stronger Epoxy-metal bonds resulting in a less adherent coat [13]. Also, increasing the ratio of APTES over a certain limit would force the formation of a thin layer of silica (shown in Fig. 5) with an unaviodable micro-cracks that further and further decrease the adhesive power of the hybrid coat [1].



Fig. 5. SEM images for a cross-section of the A5 sample showing silica agglomeration over the interface affecting the adhesion.

A thorough investigation for the sample A3 shear specimen after failure (Fig. 6) showed an adhesive failure mode, in which stresses within the network were the cause of deformation. Bond-line and cohesive failure modes did not show up during conducting of the test, which confirms that bonding has taken place between the adhesive layer and the adherend [14]. In addition, the load applied are directed to the adhesive layer that of the coat and that the results shown are of the formed hybrid network itself $[15,16]$. 


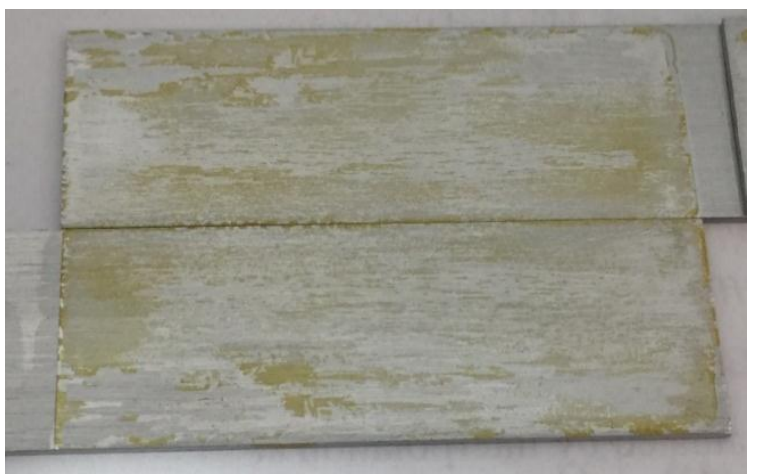

Fig. 6. Sample A3 shear specimen after failure

\subsubsection{Hardness test}

The data came out from applying the Vickers hardness test on the HV10 (10 kgf) to the different hybrids, are listed in Table 2 and shown in Fig. 7.

Table 2. Hardness (Vickers test) results.

\begin{tabular}{c|c|c|c|}
\hline \hline Sample & $\begin{array}{c}\text { Harnders } \\
\text { (APTES : DETA) } \\
\text { ratio }\end{array}$ & HV & $\begin{array}{c}\text { Mean diagonal } \\
\text { length }(\mu \mathrm{m})\end{array}$ \\
\hline A0 & $0: 1$ & 147.3 & 354.8 \\
A1 & $1: 4$ & 188.8 & 313.4 \\
A2 & $1: 1.5$ & 221.0 & 289.7 \\
A3 & $1: 0.67$ & 170.8 & 329.5 \\
A4 & $1: 0.25$ & 149.1 & 352.7 \\
A5 & $1: 0$ & 134.4 & 371.5 \\
\hline \hline
\end{tabular}

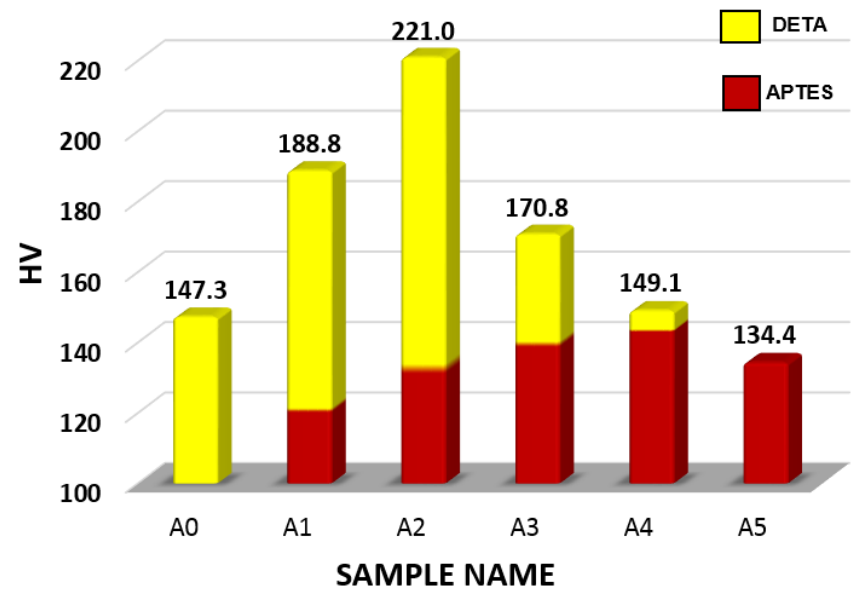

Fig. 7. Graphical representation for the hardness results

Apparently, it was thought that a more ceramic-rich hybrid network from A0 to A5 would show an increase in the hardness as a main property for ceramics. But, the results came out to show an opposing trend. It is clear from the resulted data that an increase is to be observed at first with the increase in the silica content. Increasing the silica content (increasing APTES ratio) would start the formation silica particles in clusters. Silica agglomerations would show micro-cracks within the coat affecting to a great extent to the hardness measurements. Fig. 8 shows SEM image for A5 revealing the micro-crack found in silica agglomerations. 


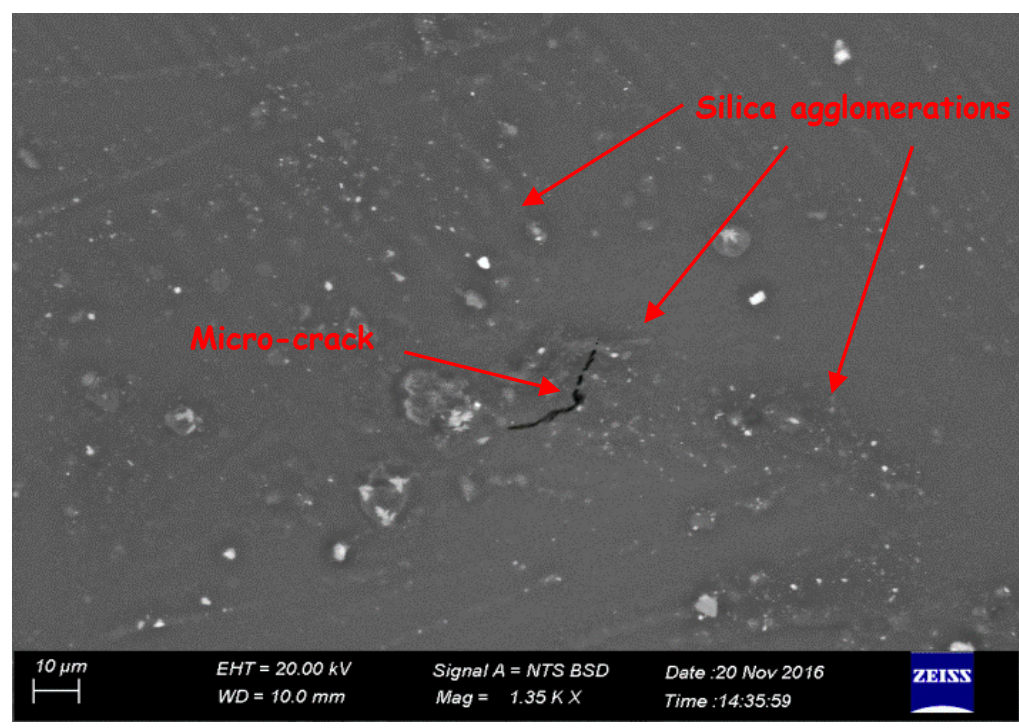

Fig. 8. SEM image for A5 sample surface of the highest silica content showing micro-cracks

A great agreement is taking place between the different mechanical properties measured. Sample A2 has recorded the best combination of mechanical properties followed by samples $\mathrm{A} 1$ and $\mathrm{A} 3$, then comes samples $\mathrm{A} 0$ and $\mathrm{A} 5$ the least.

\subsection{Thermal Gravimetric Analysis (TGA)}

TGA is used to evaluate the thermal stability and to determine the silica content involved for each hybrid composition. Combustion of a small amount of each prepared coat in a dynamic airflow from ambient temperature to $800^{\circ} \mathrm{C}$ preserving the conditions mentioned above would gives the following results shown in Table 3 . Table 3 shows the silica content for all samples in which silica content is represented by the remaining weight with respect to that originally introduced (excluding the ash content from the neat epoxy).

\begin{tabular}{c|c|c|} 
Table 3. Silica content for the prepared hybrid \\
\hline \hline & Hardners & Silica \\
Sample & $\begin{array}{c}\text { APTES : DETA) } \\
\text { ratio }\end{array}$ & $\begin{array}{c}\text { Content } \\
(\%)\end{array}$ \\
\hline Epoxy & $0: 1$ & $0.00 \%$ \\
A0 & $0: 1$ & $12.12 \%$ \\
A1 & $1: 4$ & $15.04 \%$ \\
A2 & $1: 1.5$ & $18.31 \%$ \\
A3 & $1: 0.67$ & $21.36 \%$ \\
A4 & $1: 0.25$ & $24.12 \%$ \\
A5 & $1: 0$ & $27.59 \%$ \\
\hline \hline
\end{tabular}

Fig. 9 shows the TGA thermographs of the neat epoxy along with its silica bonded hybrids. It is clear from the graphs that the neat epoxy sample has shown nearly a complete decomposition while introducing GLYMO to the Epoxy at the ratio of 1:1 had increased the silica content to $12 \pm 0.5 \%$. Using different compositions of hardners has shown that the introduction of APTES increases the inorganic content (represented in silica) of the coat. A completely APTES cured sample had shown the max. silica content of $27.6 \%$. 


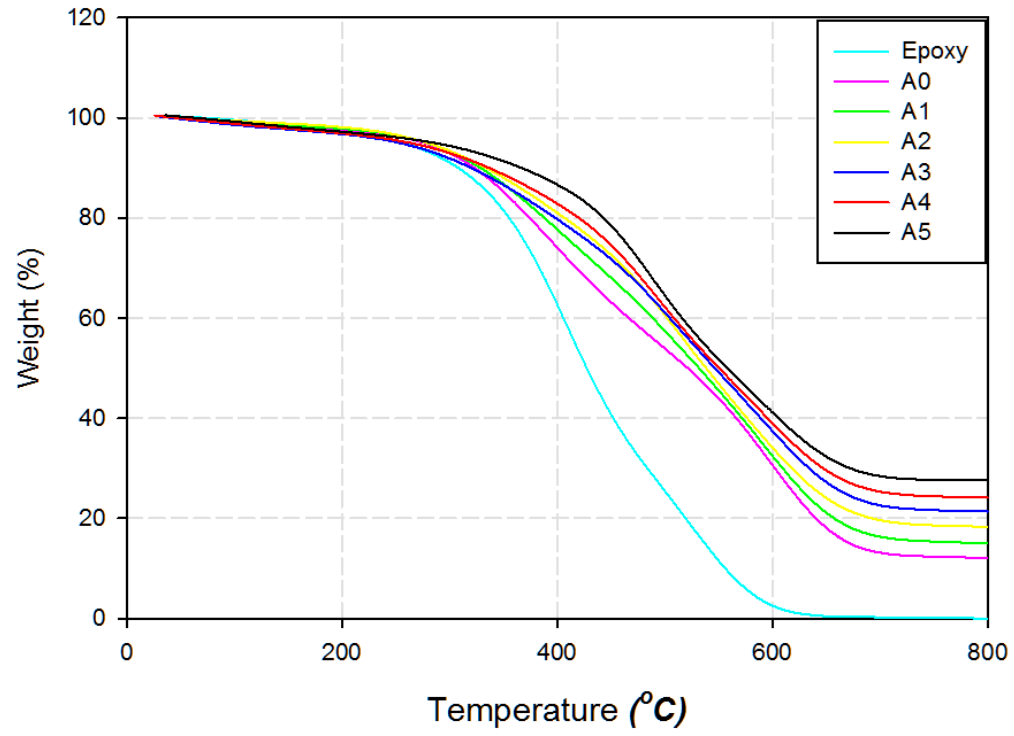

Fig. 9. TGA thermographs of the neat epoxy and the hybrid coats

Reviewing the DrTGA thermos-graphs (as in Fig. 10) shows that the thermo-oxidative degradation of epoxy and its hybrids is done over a three-stage process [17]. The TGA curves starts with a small inclination at the range of $\left(120-180^{\circ} \mathrm{C}\right)$ that corresponds to the first stage. In this stage, the loss of water adsorbed from the surrounding and that condensed from the residual hydroxyl groups of the silanol groups $(\mathrm{Si}-\mathrm{OH})$ are involved $[1,17,18]$. A second stage is associated to the breakage and the decomposition of the crosslinked organic polymer network in epoxy $[1,17]$. Then, a third oxidative-degradation stage stems from the structural phase-separation conversion or an oxidation of the aromatic rings of epoxy[19, 20]. As illustrated before, the weight retained after $800^{\circ} \mathrm{C}$ is proportional to the silica weight produced from the sol-gel process in the hybrids, which confirms that the hydrolysis and condensation processes were nearly complete after curing [17].

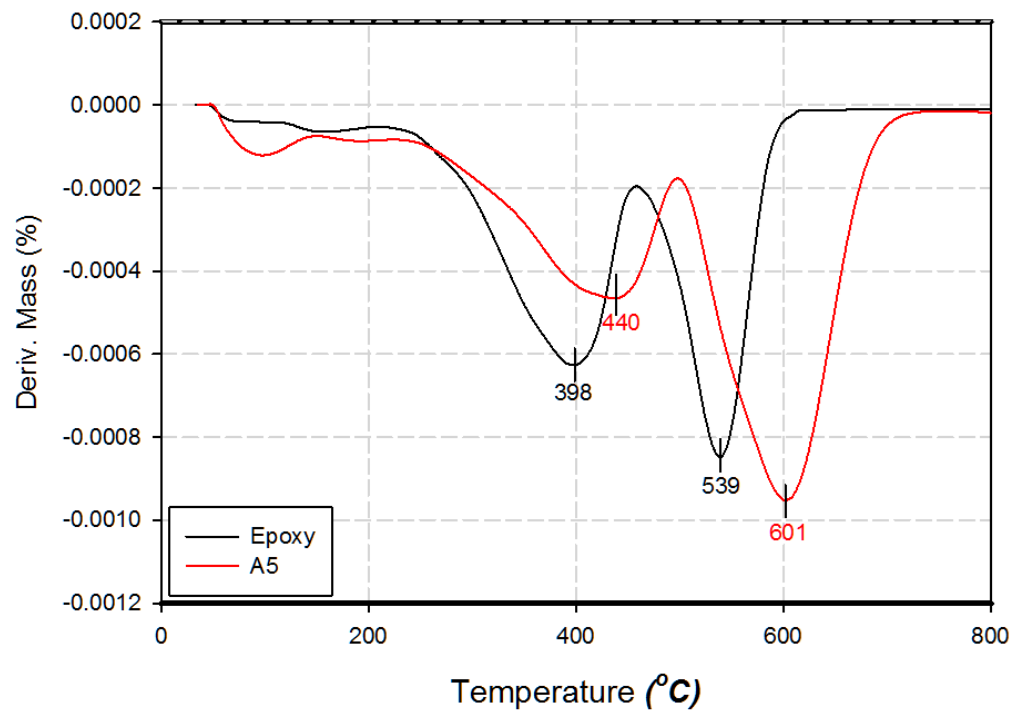

Fig. 10. DrTGA thermos-graphs of the DETA cured epoxy and the APTES cured (Epoxy/GLYMO) hybrid.

A comparison of the DrTGA of the DETA cured Epoxy and the A5 sample (the APTES cured (Epoxy/GLYMO) hybrid with the max. silica content) is shown in Fig. 10. It is obvious that a similar decomposition patterns are obtained that confirms the contribution of the organic components only to the weight loss in the hybrid materials. However, all degradation steps 
were found to occur at slower rates and higher temperatures for the silica-contained hybrid. The increased onset decomposition temperature $\left(\mathrm{T}_{\mathrm{d}}\right)$ from $398^{\circ} \mathrm{C}$ to $440^{\circ} \mathrm{C}$ is attributed to the insulating barriers created by the heat-resistant nano-silica particles on the matrix that protects the organic matrix from the thermo-oxidative degradation [17]. While the increase in the other decomposition temperature from $539^{\circ} \mathrm{C}$ to $601^{\circ} \mathrm{C}$ is attributed to the covalent bonds formed between the amino groups linked to the silica-networks and the epoxy resin that can postpone the breakdown of the aromatic rings [20]. Therefore, the introduction of silica to the thermoset epoxy coat had offered a stability to the all hybrids rather than the neat epoxy [1, $17,21]$

\subsection{Corrosion Behavior of the Hybrid Coatings}

Generally, barrier coating can protect metals for short period. During that period of time, the electrolytes can diffuse through the coating and finally reaches the coating/metal interface. This diffusion process was accompanying with decreasing of the coating impedance. The corrosion performance of barrier coatings can be predicted from the rate of change of impedance with immersion time.

Fig. 11 to Fig. 17 show the impedance and phase angle plots of A0, A1, A2, A3, A4 and A5 respectively. These coatings were applied to AA2024 substrates where the coated areas were typically $10 \mathrm{~cm}^{2}$. EIS measurements were applied on three identical samples of each combination. All these coating combinations represent hybrid sol gel coating without any loaded inhibitor i.e. represent barrier coatings.
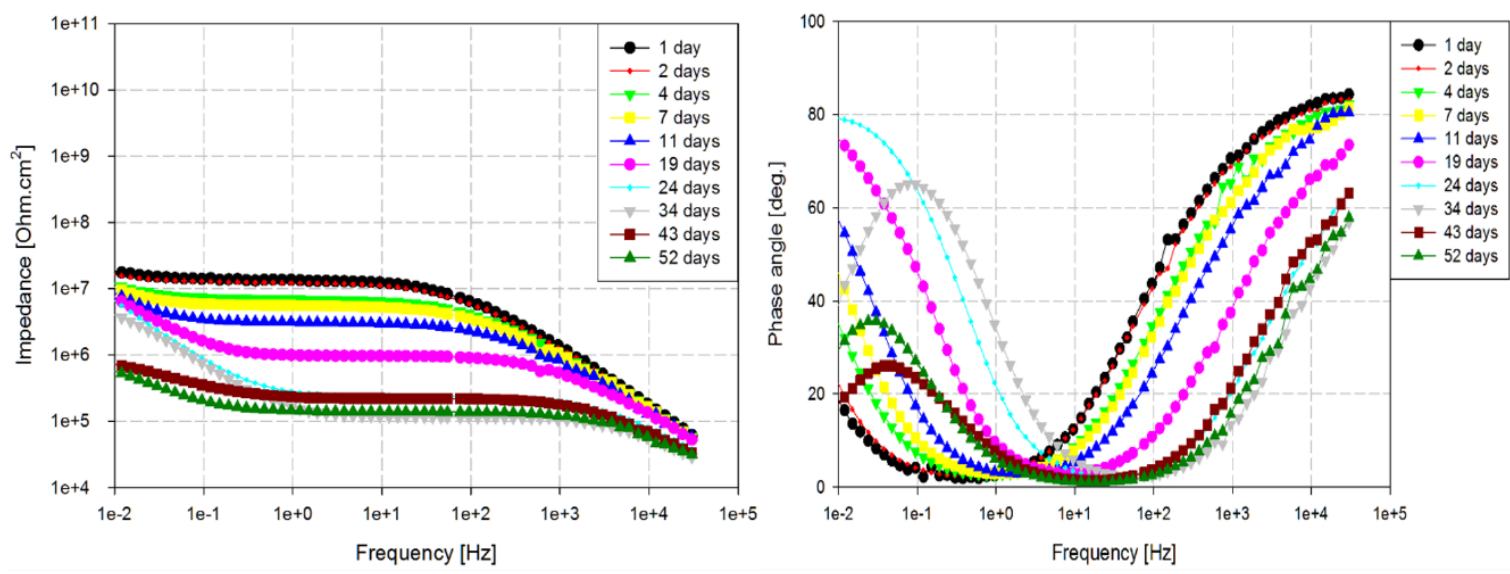

Fig. 11. Bode and phase angle plots for A0 sample
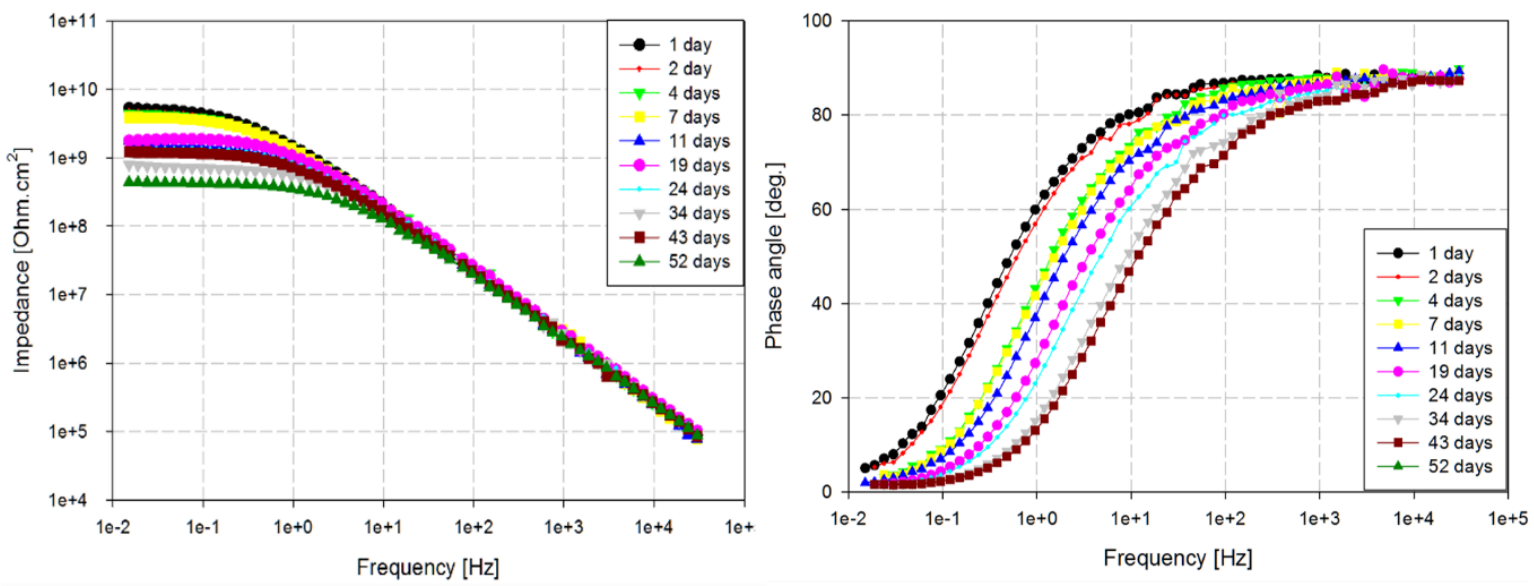

Fig. 12. Bode and phase angle plots for A1 sample 
All coatings showed a continuous decrease in the impedance with immersion time. The total impedance values, at $10 \mathrm{mHz}$, change with the APTES concentration within the sol gel matrix. During the whole immersion course, the impedance increases significantly with increase of APTES from A0 to A2 then decreases dramatically from A2 to A5.
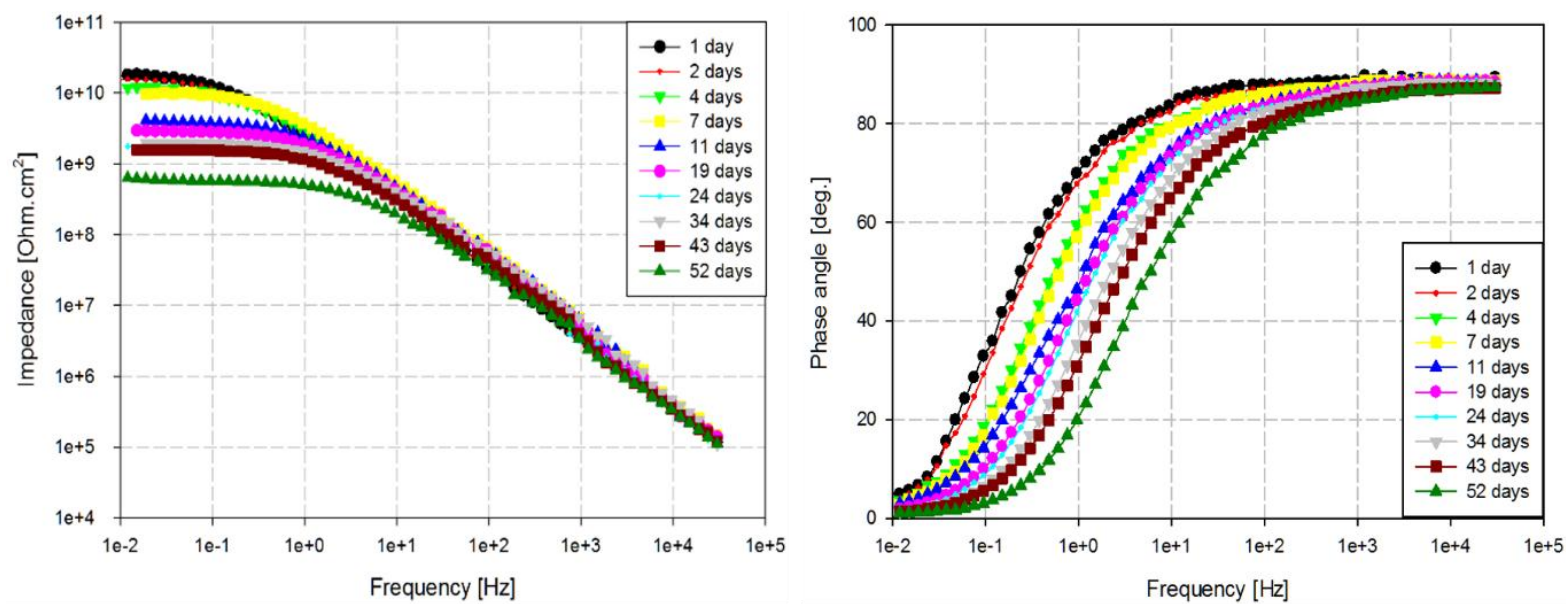

Fig. 13. Bode and phase angle plots for A2 sample
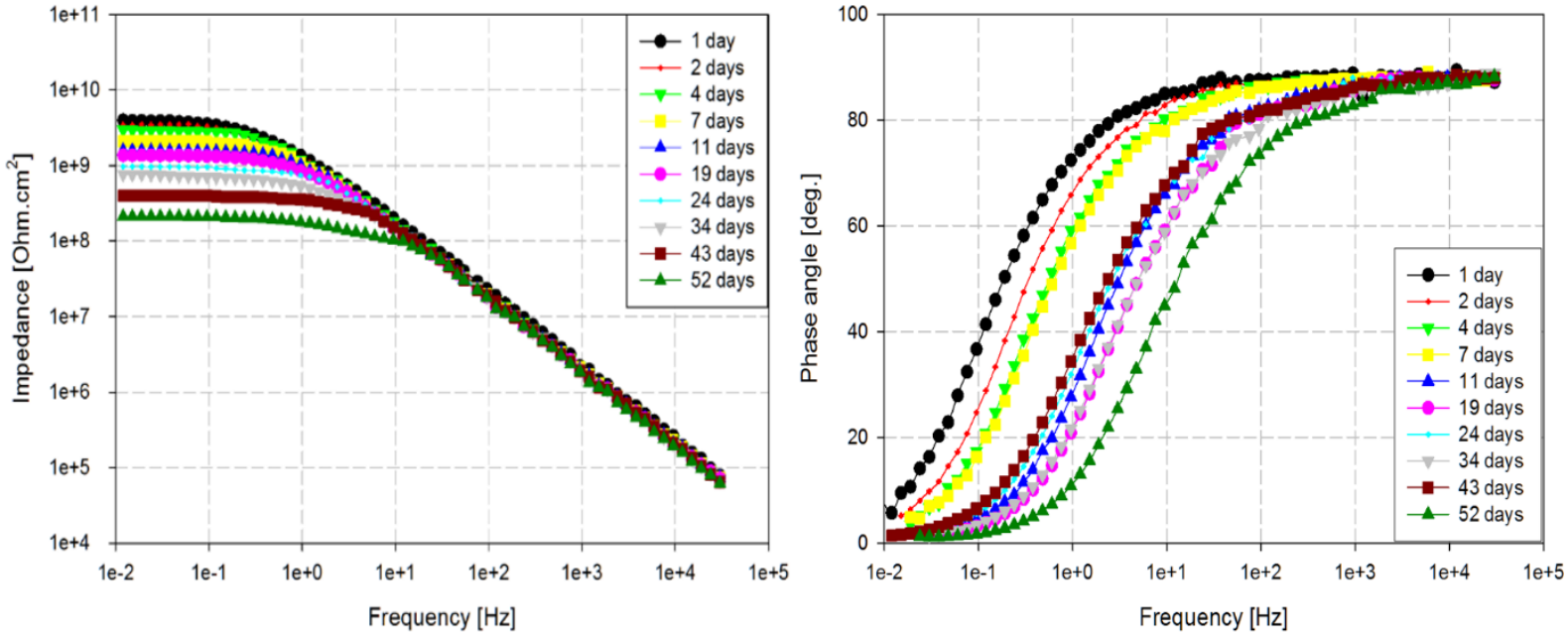

Fig. 14. Bode and phase angle plots for A3 sample
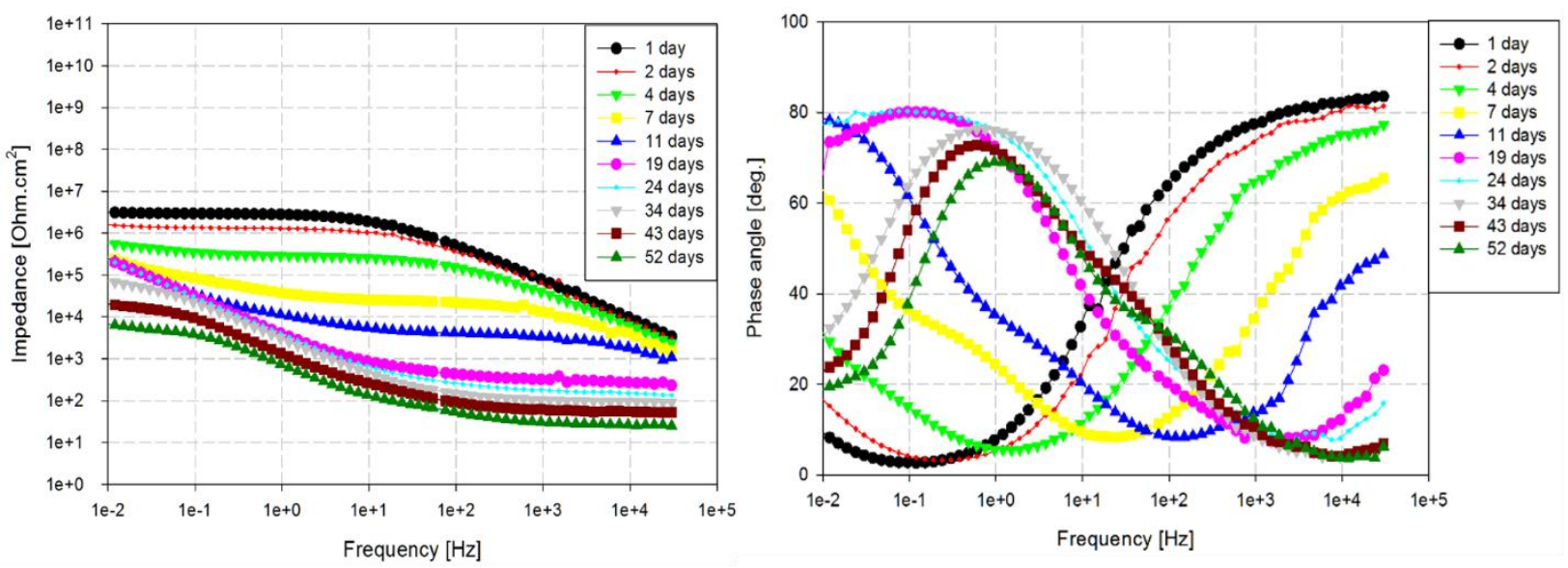

Fig. 15. Bode and phase angle plots for A4 sample

A0, A4, and A5 showed a continuous decrease in impedance in all the frequency range. This behavior is attributed to the interaction at (i) sol gel coating/ solution (high range frequency) and (ii) at the coating/metal (medium range frequency) interfaces. The former may be related 
to the less wetting properties of silica sol gel coating which appears as a high impedance (up to $10^{5} \mathrm{Ohm} . \mathrm{cm}^{2}$ at high frequency rage) accompanying with a capacitive phase angle (i.e. up to $\left.80-90^{\circ}\right)$. This phase angle decreases with immersion time due to the wetting properties of silica by time. The later interaction usually appears due to water uptake, which appears as a sharp decrease in impedance at the mid. range frequency in addition to a move of phase angle towards low frequency.
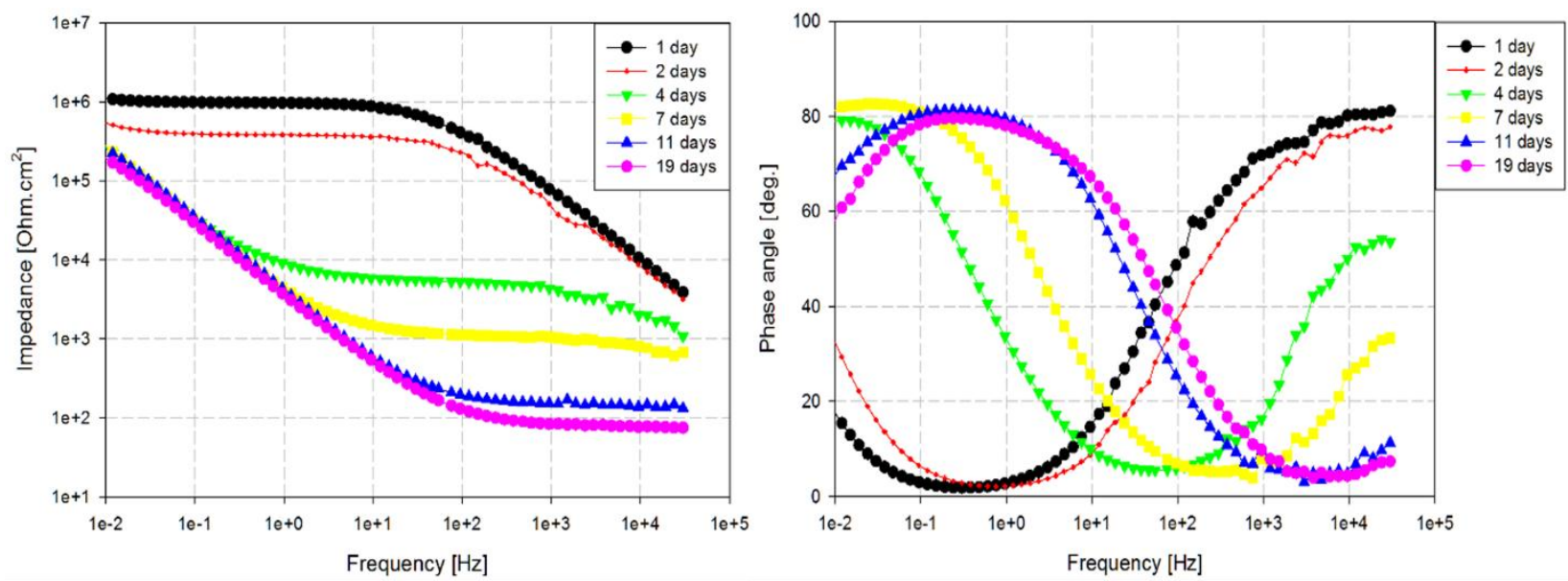

Fig. 16. Bode and phase angle plots for A5 sample

Usually, water uptake results from one or both of the following (i) growth of numerous pores through the coating leading to losing its barrier properties, and (ii) the prolonged immersion of coated metal in the electrolyte results in coating degradation. Both are indicative for a start of corrosion process which is accompanied by observation of corrosion products [22].

Samples A1, A2, and A3 showed a different behavior than that of the above samples where impedance only showed a decrease at low frequency range $(10 \mathrm{mHz})$, however, they showed stability at the mid and high range frequencies. Also, the phase angle plots of these two samples show a capacitive behavior during the course of immersion test (52 days). This behavior indicates that these coating have a high diffusion resistance.

From the above results, it can be notice that APTES concentration within hybrid epoxy-sol gel matrix has a range in which a compact homogenous coating that prevent electrolyte ingress.

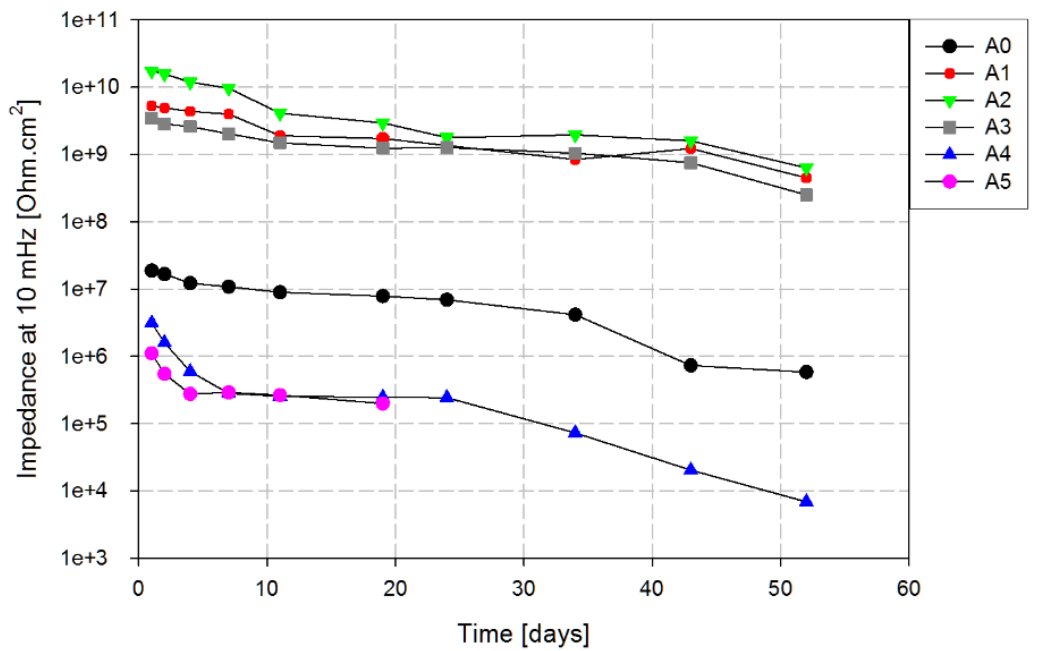

Fig. 17. Impedance at $10 \mathrm{mHz}$ for all samples during immersion time 
During pre-hydrolysis of GLYMO, small silica particles were produced. After mixing with epoxy these silica particles are not in a complete homogeneity within the formed matrix. The base coat consists mainly of equal amount of GLYMO to that of epoxy, which would form a high percentage of silica particles that would cause a low resistance of the coat to diffusion. These silica particles begin to come in homogeneity within the epoxy matrix by adding APTES [1].

By increase the concentration of APTES (A1, A2, and A3) the number of silica particles that is firmly bonded to the epoxy matrix increases forming a single compact network. That in turns would form more covalent bonds with the substrate over that of the former composition increasing the adhesive power of the coat to the surface of the metal substrate [1]. SEM images of A1, A2, and A3 showed a uniform coating free of cracks. Fig. 18 shows the SEM image of the crack-free coat of sample A2 as a representative for the three coatings.

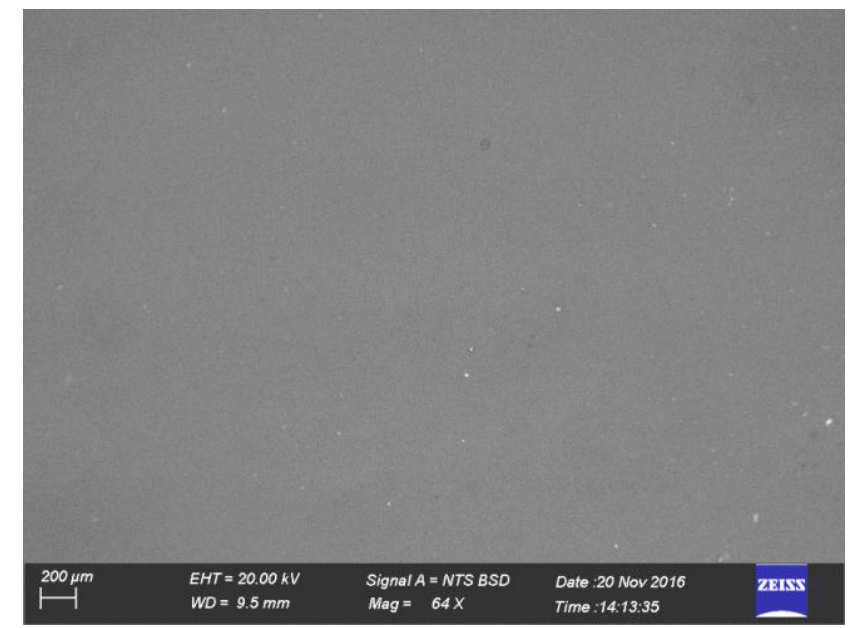

Fig. 18. The crack-free coat of A2 sample

Further increase of APTES (A4 and A5) would increase the Si-O-Al bonds in the expenses of the strong epoxy-Al bonding resulting in weakening the adhesion of the coating to the metal surface. Also, the increase in the silica content would results in an induced stresses that would enforces a fine micro-crack within the formed coat. SEM image of A4 showed in Fig. 19 clarifies the existence of some fine cracks.
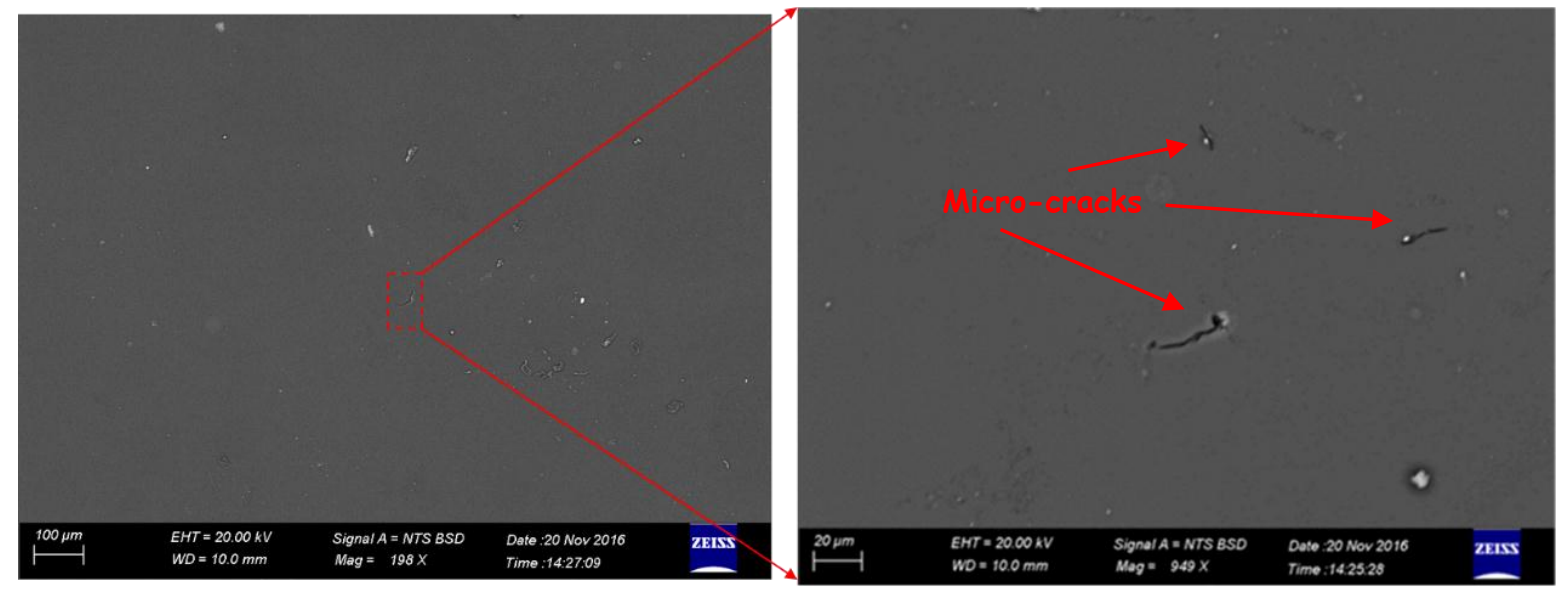

Fig. 19. Fine micro-cracks found in A4 sample

Therefore, the ingress of electrolyte though the coating to coating/metal interface would be faster and finally coating degradation more rapidly. 
According to the above discussion, the presence of APTES in the range of A1 to A3 improves diffusion-resistance throughout the epoxy-sol gel coating. The water uptake can be used to compare and evaluate the diffusion process within coatings. It was measured for all the coated samples according to equation (5) [23]:

$W_{v}=\frac{\log \left(\frac{C_{t}}{C_{o}}\right)}{\log \left(\varepsilon_{w}\right)}$

where $C_{\mathrm{t}}$ is the coating capacitance at immersion time $t, C_{\mathrm{o}}$ is the initial coating capacitance (at $t=0)$ and $\varepsilon_{\mathrm{w}}$ is the dielectric constant of water $\left(\varepsilon_{\mathrm{w}}=80\right)$ [24].

A fixed frequency of $1 \mathrm{~Hz}$ was applied to measure the capacitance of all coatings during the immersion in the $3.5 \% \mathrm{NaCl}$ corrosive solution at room temperature [25, 26]. Fig. 20 shows the water uptake for all of the coated samples (A0, A1, A2, A3, A4 and A5).

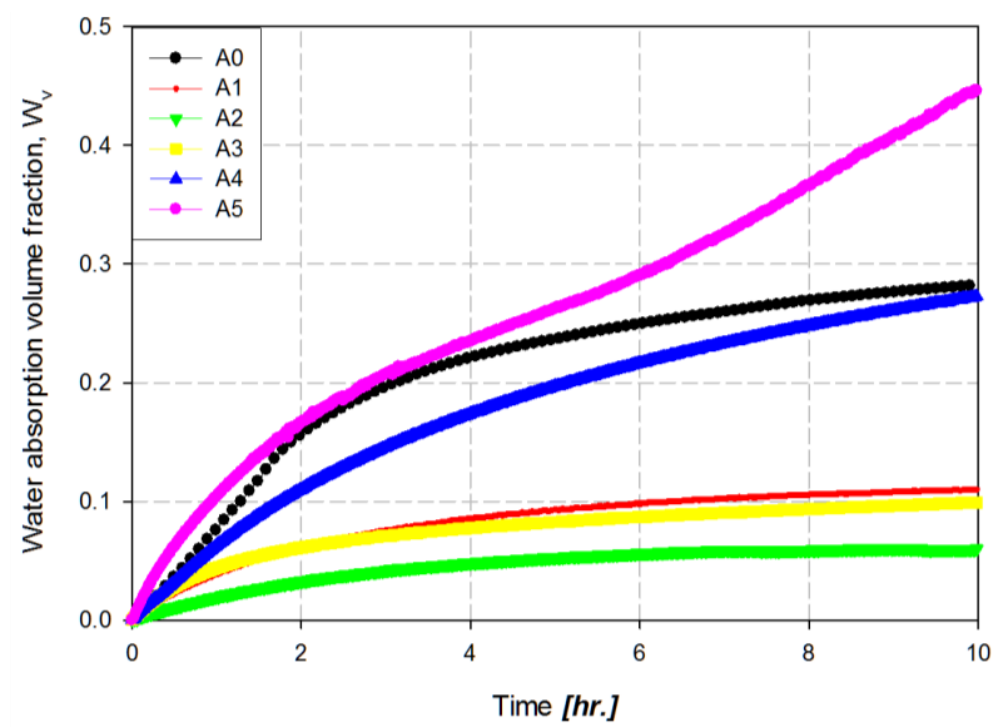

Fig. 20. Water absorption volume fraction, $W v$, versus time (t) for the various coating systems.

It is clear from the figure that all samples have abrupt increase of water absorption at the first few minutes of immersion, however, the rate of absorption decreases significantly afterwards. The rate of water absorption for A1, A2, and A3 samples seems to be smaller than that of the rest samples. Hence, it can be concluded that the presence of APTES with the concentration of A1, A2, and A3 enhanced the diffusion resistance of sol gel hybrid coatings.

\section{Conclusions}

Silica-based hybrid coatings prepared by the reaction of diglycidyl ether of bisphenol A (DGEBA) epoxy resin and 3- glycidoxypropyl trimethoxysilane (GLYMO) in the presence of 3-Aminopropyl triethoxysilane (APTES) and diethylene triamine (DETA) were prepared and characterized. Confidently, FTIR spectra confirmed the formation of silica domains with the epoxy matrix. It was observed that the adhesion strength has obviously risen with increasing the APTES content to that of the A2 sample (APTES:DETA ratio of 1:1.5 by wt.). Also, the same sample has recorded the highest hardness of $221.0 \mathrm{HV}$ compared to other compositions. On the other side, increasing the silica content was observed to increase the thermal stability of hybrid coat, in which sample A5 (with silica content up to 27.59\%) has shown higher thermal stability rather than the other hybrids and the neat epoxy. The EIS experimental data was analyzed for the prepared coat on AA2024 against 3.5\% $\mathrm{NaCl}$ solution. Sample A2 has shown the best protection against corrosion among the prepared hybrids. 


\section{References}

[1] E. Bakhshandeh, A. Jannesari, Z. Ranjbar, S. Sobhani, and M. R. Saeb, "Anti-corrosion hybrid coatings based on epoxy-silica nano-composites: Toward relationship between the morphology and EIS data", Progress in Organic Coatings, vol. 77, pp. 1169-1183, 2014.

[2] S. R. Davis, A. R. Brough, and A. Atkinson, "Formation of silica/epoxy hybrid network polymers", Journal of non-crystalline solids, vol. 315, pp. 197-205, 2003.

[3] K. Xhanari and M. Finšgar, "Organic corrosion inhibitors for aluminum and its alloys in chloride and alkaline solutions: A review", Arabian Journal of Chemistry, 2016.

[4] R. G. Buchheit, R. P. Grant, P. F. Hlava, B. Mckenzie, and G. L. Zender, "Local dissolution phenomena associated with $\mathrm{S}$ phase $(\mathrm{Al} 2 \mathrm{CuMg})$ particles in aluminum alloy 2024T3", Journal of the electrochemical society, vol. 144, p. 2621, 1997.

[5] K. A. Yasakau, S. Kallip, M. L. Zheludkevich, and M. G. S. Ferreira, "Active corrosion protection of AA2024 by sol-gel coatings with cerium molybdate nanowires", Electrochimica Acta, vol. 112, pp. 236-246, 2013.

[6] J. Coates, "Interpretation of infrared spectra, a practical approach", Encyclopedia of analytical chemistry, 2006.

[7] V. Tagliazucca, "Nanostructured hybrid organic/inorganic materials by the nanobuilding blocks (NBB) approach", Doctoral dissertation, University of Trento, 2010.

[8] I. M. Šapić, L. Bistričić, V. Volovšek, and V. Dananić, "Vibrational Analysis of 3glycidoxypropyltrimethoxysilane polymer", Macromolecular Symposia, pp. 122-129, 2014.

[9] P. Cardiano, S. Sergi, M. Lazzari, and P. Piraino, "Epoxy-silica polymers as restoration materials", Polymer, vol. 43, pp. 6635-6640, 2002.

[10] P. Underhill, G. Goring, and D. DuQuesnay, "A study of the deposition of 3glycidoxypropyltrimethoxysilane on aluminum", International journal of adhesion and adhesives, vol. 18, pp. 307-311, 1998.

[11] W. Zhang, A. A. Dehghani-Sanij, and R. S. Blackburn, "IR study on hydrogen bonding in epoxy resin-silica nanocomposites", Progress in Natural Science, vol. 18, pp. 801$805,2008$.

[12] R. M. Almeida and C. G. Pantano, "Structural investigation of silica gel films by infrared spectroscopy", Journal of Applied Physics, vol. 68, pp. 4225-4232, 1990.

[13] R. D. Adams, "Adhesive bonding: science, technology and applications", Elsevier, 2005.

[14] R. H. Goudarzi and M. R. Khedmati, "An experimental investigation of static load capacity of AL-GFRP adhesively bonded single lap and double butt lap joints," Latin American Journal of Solids and Structures, vol. 12, pp. 1583-1594, 2015.

[15] J. D. C. San Román, "Experiments on epoxy, polyurethane and ADP adhesives", Composite Structure Laboratory, vol. 1b/1, 2005.

[16] J. D. C. San Román, "Experiments on Double-lap Joints with Epoxy, Polyurethane and ADP Adhesives", Composite Structure Laboratory, vol. 1b/2, 2005.

[17] Z. Ahmad and F. Al-Sagheer, "Preparation and characterization of epoxy-silica networks chemically bonded through aminophenyl-trimethoxysilane", Journal of SolGel Science and Technology, vol. 72, pp. 334-343, 2014.

[18] J. Z. Zheng, X. P. Zhou, X. L. Xie, and Y. W. Mai, "Silica hybrid particles with nanometre polymer shells and their influence on the toughening of polypropylene", Nanoscale, vol. 2, pp. 2269-2274, 2010.

[19] Y. Liu, Z. Du, C. Zhang, and H. Li, "Thermal degradation of bisphenol A type novolac epoxy resin cured with 4, 4'-diaminodiphenyl sulfone", International Journal of Polymer Analysis and Characterization, vol. 11, pp. 299-315, 2006. 
[20] Z. Xi, H. Qingliang, and G. Hongbo, "Polyaniline stabilized barium titanate nanoparticles reinforced epoxy nanocomposites with high dielectric permittivity and reduced flammability", J Mater Chem C, vol. 1, p. 2886, 2013.

[21] K. Y. Huang, C. J. Weng, S. Y. Lin, Y. H. Yu, and J. M. Yeh, "Preparation and anticorrosive properties of hybrid coatings based on epoxy-silica hybrid materials", Journal of applied polymer science, vol. 112, pp. 1933-1942, 2009.

[22] D. J. Carbonell, A. García-Casas, J. Izquierdo, R. M. Souto, J. C. Galván, and A. Jiménez-Morales, "Scanning electrochemical microscopy characterization of sol-gel coatings applied on AA2024-T3 substrate for corrosion protection", Corrosion Science, vol. 111, pp. 625-636, 2016.

[23] D. Zhu and W. J. van Ooij, "Corrosion protection of AA 2024-T3 by bis-[3(triethoxysilyl)propyl]tetrasulfide in sodium chloride solution.: Part 2: mechanism for corrosion protection", Corrosion Science, vol. 45, pp. 2177-2197, 2003.

[24] J. Escobar, M. Poorteman, L. Dumas, L. Bonnaud, P. Dubois, and M.-G. Olivier, "Thermal curing study of bisphenol A benzoxazine for barrier coating applications on 1050 aluminum alloy", Progress in Organic Coatings, vol. 79, pp. 53-61, 2015.

[25] N. Meis, L. van der Ven, R. van Benthem, and G. de With, "Extreme wet adhesion of a novel epoxy-amine coating on aluminum alloy 2024-T3", Progress in Organic Coatings, vol. 77, pp. 176-183, 2014.

[26] M. Gobara, H. Kamel, R. Akid, and A. Baraka, "Corrosion behaviour of AA2024 coated with an acid-soluble collagen/hybrid silica sol-gel matrix", Progress in Organic Coatings, vol. 89, pp. 57-66, 2015.

[27] E. Bakhshandeh, A. Jannesari, Z. Ranjbar, S. Sobhani, and M. R. Saeb, "Anti-corrosion hybrid coatings based on epoxy-silica nano-composites: Toward relationship between the morphology and EIS data", Progress in Organic Coatings, vol. 77, pp. 1169-1183, 2014. 